\title{
NEW APPROACHES TO GENETIC THERAPIES FOR CYSTIC FIBROSIS
}

A. Christopher Boyd1, Shuling Guo2, Lulu Huang2, Batsheva Kerem3,4, Yifat S. Oren4, Amy J. Walker5, Stephen L. Hart5

1 University of Edinburgh, Centre for Genomic and Experimental Medicine, University of Edinburgh and Institute of Genetics \& Molecular Medicine, Western General Hospital, Edinburgh UK; UK Cystic Fibrosis Gene Therapy Consortium, www.cfgenetherapy.org.uk 2 Antisense Drug Discovery, Ionis Pharmaceuticals, Carlsbad, California, USA 3 Department of Genetics, The Life Sciences Institute, The Hebrew University of Jerusalem, Jerusalem Israel

4 SpliSenseTherapeutics, Givat Ram Campus, Hebrew University, Jerusalem, Israel

5 Department of Genetics and Genomic Medicine, UCL Great Ormond Street Institute of Child Health, London UK

\section{Corresponding author: Stephen L Hart}

Keywords: cystic fibrosis; gene therapy; antisense oligonucleotides; siRNA; mRNA splicing; ENaC; CFTR; liposomes, nanoparticles

\section{Abstract}

Gene therapy offers great promise for cystic fibrosis which has never been quite fulfilled due to the challenges of delivering sufficient amounts of the CFTR gene and expression persistence for a sufficient period of time in the lungs to have any effect. Initial trials explored both viral and non-viral vectors but failed to achieve a significant breakthrough. However, in recent years, new opportunities have emerged that exploit our increased knowledge and understanding of the biology of CF and the airway epithelium. New technologies include 
new viral and non-viral vector approaches to delivery, but also alternative nucleic acid technologies including oligonucleotides and siRNA approaches for gene silencing and gene splicing, described in this review. We also briefly discuss other emerging technologies including mRNA and CRISPR gene editing that are advancing rapidly. 


\section{Introduction}

Cystic Fibrosis (CF) is caused by mutations in the gene encoding the cystic fibrosis transmembrane conductance regulator (CFTR), a cyclic AMP-activated chloride channel. Mutations in CFTR lead to imbalanced water and ion movement across the airway epithelium, resulting in thickened mucus, chronic bacterial infection and inflammation, with progressive loss of pulmonary function. CFTR modulators offer therapeutic opportunities for a wide range of CFTR mutations, [1-3], which should enable treatment for approximately $90 \%$ of CF patients. However, a substantial number of patients, such as those with class I mutations, including premature termination codons (PTCs) and other variants where CFTR protein is not produced, are not amenable to modulator therapies. In addition, while modulators are well tolerated for most patients, Lumacaftor-Ivacaftor therapy has been associated with ocular and hepatic side effects in some patients, while dyspnea may affect others [4]. Therefore, for patients where modulators are ineffective or not well-tolerated, alternative therapies are required and there are now numerous genetic approaches under development that offer promise for these groups of patients including novel siRNA and oligodeoxynucleotides in addition to plasmid-mediated and viral therapies, which are discussed in this review (Table 1).

CF gene therapy clinical trials by delivery of CFTR performed with Adeno-associated virus $(\mathrm{AAV})$ and adenovirus, as well as non-viral liposome formulations continue to offer promise but so far have not led to the hoped-for clinical breakthroughs that this approach offers $[5$, 6]. In this review, we report a recent liposomal trial for CF gene therapy, the largest ever gene therapy trial for $\mathrm{CF}[7], \mathrm{m}$ and the development of a novel lentiviral vector that is progressing to clinical trials [8]. Other genetic approaches to therapy described in this review include alternative ion channel approaches by inhibition of the epithelial sodium channel 
(ENaC) (Fig. 1) via gymnostic delivery of antisense oligonucleotides (ASO), and by a nanoparticle/short interfering RNA (siRNA) approach. Each of these approaches could potentially be applied to any CF patient regardless of mutation class. Finally, in contrast to, an ASO approach highly specific to splice mutations is described for the correction of the CFTR splicing mutation $3849+10 \mathrm{~kb}$ C>T.

This review was based on a symposium session presented at the 16th ECFS Basic Science Conference, Dubrovnik, Croatia, 27 to 30 March, 2019.

\section{SiRNA Targeting of the Epithelial Sodium Channel}

Increased sodium absorption in the CF airways has been proposed to lead to increased water absorption depleting the overlaying watery, periciliary liquid (PCL), and increasing the thickness and stickiness of the mucus $[9,10]$. The dehydrated airways and impaired mucociliary clearance encourage chronic bacterial infections and an increasing body of evidence supports the hypothesis for the role of $\mathrm{ENaC}$ in $\mathrm{CF}$ lung pathology. This includes the observation of dehydrated, CF-type symptoms of transgenic ENaC-overexpressing mice [11] and normalisation of sodium and fluid absorption in CF cells after silencing of the $\mathrm{ENaC}$ regulators, ciliary neurotrophic factor (CNTFR) and diacyl glycerol kinase iota (DGKI) [12]. Therefore, inhibition of $\mathrm{ENaC}$ is a promising therapeutic possibility for $\mathrm{CF}$ to correct hydration of the airway surface liquid [13]. While small molecule drugs that target $\mathrm{ENaC}$ have been in development for several years, no clinical therapy has emerged yet and so genetic strategies are in development that offer an alternative solution [14].

RNA interference (RNAi) is a powerful, naturally occurring technique for regulating gene expression that was first described in 1998 [15] and, since then, has been a major focus for research into therapeutics using siRNA. The first therapy, Onpattro ${ }^{\mathrm{TM}}$ (Patisiran), was approved in 2019 and comprises a lipid nanoparticle (LNP) siRNA formulation approved for 
the treatment of transthyretin amyloidosis (TTR), a disease involving the liver $[12,13]$. We are building on this breakthrough to develop siRNA-mediated therapy for cystic fibrosis by silencing of the $\alpha \mathrm{ENaC}$ chain with a specific siRNA ( $\operatorname{siENaC\alpha }$ ), delivered with a novel targeted lipid (L)/ peptide (P)/siRNA (R) nanoparticle. The LPR nanoparticle comprises mixtures of cationic liposomes $(\mathrm{L})$ and cationic targeting peptides $(\mathrm{P})$ which self-assemble, electrostatically on mixing with siRNA $(R)$ to form LPR nanocomplexes $[16,17]$. The peptide mediates packaging of siRNA through a cationic, sixteen-lysine (K16) motif and targeting through a seven-amino acid motif, SERSMNF, for targeting respiratory epithelial cells [18]. The liposome component (DOTMA/DOPE) enhances transfection efficiency by destabilising the endosomal bilayer allowing release of the nucleic acid to the cytoplasm before endosomal degradation occurs.

LPR transfections performed in CFBE ALI cultures achieved $30 \%$ silencing of $\alpha E N a C$ in ALI, increasing to approximately $50 \%$ from 3 repeat doses, as determined by qRT-PCR [19]. This level of silencing was shown to be sufficient to restore mucociliary properties of the epithelium, reduced mucus protein concentration, increased airway surface liquid depth and increased ciliary beat frequency [13]. In addition, the amiloride-responsive, short circuit current was reduced, indicating reduced $\mathrm{ENaC}$ channel activity [19]. In vivo, murine $\alpha \mathrm{ENaC}$ was also silenced $30 \%$ which was enhanced to $50 \%$ by three repeat doses administered at 48h intervals [19]. Others have proposed that this level of silencing of ENaC in CF should be sufficient to restore normal salt and fluid homeostasis in the airways while higher levels of silencing could be deleterious, leading to oedema in the lung [12].

\section{Antisense oligonucleotide approaches to CF therapy.}

Antisense technology is a validated drug discovery platform that enables selective targeting of genes of interest. Antisense oligonucleotides (ASOs) bind specifically to their RNA targets through Watson-Crick base pairing to form DNA-RNA heteroduplexes that recruit RNase 
$\mathrm{H} 1$ leading to the degradation of the target RNA strand. In addition, uniformly modified ASOs can also serve as "steric blockers" to modulate mRNA processing and translation to upregulate specific gene expression [20]. As of today, five antisense therapies from lonis have been approved for the treatments of several severe genetic diseases including spinal muscular atrophy, hereditary transthyretin-mediated amyloidosis, and familial chylomicronemia syndrome [20]. Inhaled ASO via aerosol delivery is an emerging therapeutic modality for respiratory diseases. with ASO distribution to multiple cell types achieved, including airway epithelial cells where CFTR function is impaired in CF [21, 22]. In addition, ASO aerosol delivery is well-tolerated in rodents, non-human primates and humans

One strategy to ameliorate the CF phenotype in a mutation-agnostic manner is to reduce the activity of the epithelial sodium channel $(\mathrm{ENaC})$ protein, as its hyperactivity leads to airway surface dehydration and mucus accumulation in the lungs of CF patients [8,9]. We have developed ASOs that target ENaC mRNA and demonstrated that in murine CF-like models, aerosol delivered ASO reduces ENaC expression leading to significant improvement of disease phenotypes including airway hyperresponsiveness, goblet cell metaplasia, mucus overproduction and inflammation with minimum systemic exposure [23]. $\mathrm{ENaC} A S O$ is currently in phase I clinical trial.

Another mutation-agnostic strategy is to upregulate CFTR translation via steric blocking ASOs as it was reported that CFTR translation is regulated through the translation regulatory elements in its mRNA. We have previously demonstrated that uniformly modified ASOs can bind to translation regulatory elements in the $5^{\prime}$ untranslated region (UTR) of a mRNA to upregulate its translation [24]. With steric blocking ASOs that specifically bind to 5'-UTR of the CFTR mRNA, we successfully increased CFTR protein expression, which led to 
significant CFTR function improvement when combined with CFTR correctors in CF patientderived primary cells [25].

A third strategy, which is specific to CFTR with nonsense mutations, is to upregulate the expression of CFTR nonsense alleles using ASOs targeting the nonsense mediated decay (NMD) pathway and translation termination machinery. We have previously successfully applied this strategy in a hemophilia mouse model with nonsense mutation [26]. In cells with CFTR-W1282X mutation, we demonstrated that ASO-mediated reduction of NMD factor SMG1 upregulates $W 1282 X$ mRNA and protein expression, which lead to improved CFTR channel activity [27]. Furthermore, ASO mediated reduction of translation termination factors exerts synergistic effect to increase readthrough at PTC in combination with small molecule readthrough agents [26]. We are currently investigating the effect of ASO treatment in various CFTR nonsense mutants and the safety of ASO-mediated NMD inhibition and translational readthrough in the lung.

In summary, antisense technology can provide promising therapies for CF, especially patients with nonsense mutations.

\section{Oligonucleotides for Correction of CFTR mutations that Cause Splice Defects}

A significant proportion of disease-causing mutations in humans affects pre-mRNA splicing. Among these are mutations affecting non-canonical splicing motifs leading to both aberrantly and correctly spliced transcripts [28] Disease severity in patients carrying these mutations is highly variable and correlates with the level of aberrantly spliced transcripts (reviewed in [29]). 
One novel therapeutic approach for genetic disorders caused by splicing mutations is based on the administration of Antisense Oligonucleotides (ASOs) [30]. ASOs are single stranded short synthetic RNA-like molecules that are chemically modified to improve their ability to specifically recognize their target RNAs, confer resistance to nucleases and provide favourable pharmacokinetic properties [31]. The potential of ASOs as a therapeutic approach for splicing mutations was demonstrated in several human genetic diseases including Spinomuscular atrophy. Recently a very efficient ASO-based drug (SPINRAZA) was approved by the FDA for these patients (FDA approves first drug for spinal muscular atrophy $2017 \quad$ (https://www.fda.gov/newsevents/newsroom/pressannouncements/ ucm534611.htm).

In light of these exciting supporting data, ASO-based approaches have great therapeutic potential for CF patients carrying non-canonical splicing mutations. As a model, we focused on the $3849+10 \mathrm{~kb}$ C-to-T splicing mutation, which leads to inclusion of a cryptic exon in the mature mRNA. Previous work showed that splicing modulation of this mutation by ASOs was possible [6]. In an attempt to develop an efficient ASO-based drug, we designed 2'-Omethyl phosphorothioate-modified (2'-OMe) ASOs, targeted to prevent the recognition of the cryptic exon. Screening of these ASOs led to the identification of several ASOs that significantly modulated the splicing pattern of this mutation. Importantly, we demonstrated that these ASOs restored the CFTR channel function in primary human nasal epithelial cells (HNEs) of patients carrying the $3849+10 \mathrm{~kb}$ C-to-T mutation. For improvement of free ASO uptake, we recently synthesized the lead ASOs with the 2'-O-(2-methoxyethyl)oligoribonucleotide phosphorothioate (2'-MOE) backbone. This chemistry further improved the efficiency and potency of the ASO, therefore enabling the use of lower ASO concentrations to fully restore the CFTR function in HNEs. Altogether, our results indicate that ASOs targeted to mask splicing motifs in the CFTR gene can increase the correct 
splicing of CFTR, leading to restoration of channel function. These results highlight the potential of our lead ASO as a therapeutic approach for CF patients carrying splicing mutations.

\section{Gene Therapy Perspectives}

In vivo use of $\mathrm{AAV}$ for $\mathrm{CF}$ is hampered by pre-existing immunity which excludes many patients from treatment while their immunogenicity is problematic if life-long, repeated delivery is required although solutions have been suggested [32]. Lentiviral vectors of different pseudotypes are also in development for in vivo CF therapy, for example by the UK CF Gene Therapy Consortium (UKCFGTC: http://www.cfgenetherapy.org.uk), offering prospects of long term gene expression in the lung but also carrying the risk of insertional oncogenesis, although in vivo studies so far have not shown any evidence of this [33]. The UKCFGTC viral gene therapy product comprises the lentivirus SIV pseudotyped with the F and $\mathrm{HN}$ proteins of Sendai virus to enable airway epithelial cell entry [29]. The genotoxic risk of this product is mitigated by the presence of self-inactivating (enhancer-free) long terminal repeats (thus minimising readthrough transcription) [30], and by the terminally differentiated, nondividing nature of the target epithelial cells. Importantly, the vector expresses $10-100$ fold more CFTR than the non-viral product and can be repeatedly delivered to mouse lungs [31]. The UKCFGTC has partnered with Boehringer Ingelheim and Oxford BioMedica to complete the pre-clinical work necessary to enable a first-in-human trial of this lentiviral product [www.boehringer-ingelheim.com/press-release/newpartnership-develop-gene-therapy-cystic-fibrosis].

Because of concerns over viral vectors, non-viral liposomes have been evaluated more than any other vector [6]. The UKCFGTC developed such a product composed of the cationic liposome GL67A [32] and a novel plasmid pGM169 lacking pro-inflammatory CpG sequences and expressing CFTR cDNA under control of a long-acting promoter [33]. In 
2012-2014, pGM169/GL67A was tested in a Phase 2b randomised controlled trial conducted at the Royal Brompton Hospital (London) and the Western General Hospital (Edinburgh) [34]. $116 \mathrm{CF}$ patients, unselected for genotype, completed the protocol. Each received at least nine doses of nebulised pGM169/GL67A or placebo at 28 day intervals. The primary endpoint was the relative change in percentage predicted FEV1 over the 12 month period. There was a modest, statistically significant $(p=0.046)$ treatment effect of $3.7 \%$ reflected in a relative stabilisation of FEV1 in the active group compared to a decline in FEV1 in the placebo group [34]. No safety concerns were raised, and secondary outcomes overall favoured the active group. These results established for the first time that gene therapy was capable of favourably modulating CF lung function.

\section{Future Studies}

Gene therapy for CF has proven to be more problematic than first anticipated and these problems largely relate to barrier to transfection in the lung from the mucociliary barrier to the intracellular barriers to transfection of the post-mitotic cells lining the airways [34]. These mucociliary barriers in the airways present major challenges in the development of novel genetic therapies and so vectors are required that are specifically designed to better overcome these barriers and several new approaches are in development by viral and nonviral approaches [35]. On the other hand, although it may be somewhat counter-intuitive, oligonucleotides, as reported in this review, appear to be taken up with sufficient efficiency that a liposomal carrier is not required, which also has the advantage of greatly simplifying the production process.

The development of viral vectors including AAV [36, 37] and lentiviral vectors [8] continues for CFTR gene replacement therapies, but other technologies are also advancing rapidly, each of which offers different advantages and disadvantages (Table 1). CFTR mRNA is one of the most promising new approaches to therapy of $\mathrm{CF}[38,39]$ with 
encouraging Phase I/II clinical trial results announced recently (Translate Bio;

https://tinyurl.com/y6fhv2g2). Advantages of mRNA over pDNA therapy include the cytoplasmic location of the translational machinery, pre-empting the need for nuclear uptake, which eliminates one of the main barriers limiting pDNA efficiency, and so greatly enhances transfection [40]. Further, mRNA does not pose the risk of insertional mutagenesis that has to be considered for plasmid DNA-based gene therapy. Messenger RNA therapies however are highly dependent on efficient nanoparticle delivery systems that can be repeatedly delivered and so it is likely there will be continued developments in this area in the coming years.

CRISPR gene editing for genetic therapies has emerged in recent years and early studies in CF indicate its potential to specifically repair CFTR mutations [41-45]. Viral or nonviral carriers of some kind will be required for delivery of CRISPR which will face the same barriers as experienced for gene therapy. AAV for CF gene editing has found limited application so far due to the vectors inherent packaging constraints. Lentiviral vectors, as for CFTR gene therapy, offer the potential advantages of stable expression of the CRISPR components. while increasing the risk of off-target double strand breaks, in addition to the risk of insertional oncogenesis [46]. Non-viral approaches permit delivery of Cas nucleases as either an mRNA or as the preformed ribonucleoprotein (RNP) complex, offering greater efficiency than non-viral plasmid-mediated transfection of Cas9 and gRNA along with greater safety than lentiviral or AAV vectors by the transient nature of mRNA or RNP [41]. Another interesting possibility under investigation is to edit epithelial progenitor cells, either autologous induced pluripotential stem cells or (iPSCs) or basal cells, and use these as the therapy by engraftment into the CF lung [47-49]. This approach has the advantage of enabling high efficiency editing to be performed ex vivo although there remain challenges in expanding and engrafting the corrected cells back into the original donor. 
A further challenge to consider is that there are numerous cell types in the airway epithelium including goblet, ciliated, Clara cells and others in the pseudostratified airway epithelium, which have recently been characterised in detail by single cell RNA sequencing (scRNAseq) analysis, creating a lung atlas $[50,51]$. These studies led to the description of ionocytes, rare cells comprising $<1 \%$ of the airway epithelium, that express more than $50 \%$ of the CFTR, although, it was long recognised that the airway epithelium contained highand low-CFTR expressing cells [52]. Each cell type plays an important role in the physiological function of the airways and their protection from infection. It is not yet clear how important it will be to target specific cell types within the epithelium, particularly for gene editing approaches.

\section{Summary}

This review highlights new genetic approaches to therapy of CF involving oligonucleotides and siRNA. These approaches bypass the some of the obstacles to CF gene therapy by targeting mRNA as the therapeutic target $(\mathrm{ENaC})$, or by correcting a splice defect $(3849+10 \mathrm{~kb}$ C $>T)$. The siRNA approach requires a novel, targeted nanoparticle formulation

but the ASO approaches have no requirement for a carrier. With other therapies also in development involving CFTR mRNA and gene editing with CRISPR, as well as new viral and non-viral vector formulations, prospects for CF gene and genetic therapies have never been more promising provided the delivery issues can be overcome.

\section{Conflict of interest}

SH holds equity in Nanogenics Ltd, a non-viral gene therapy company. SG and LH are employees and stockholders of IONIS Pharmaceuticals. BK holds equity in SpliSense.

\section{Acknowledgments}


SH and AW are supported by the CF Trust and NIHR Great Ormond Street Hospital

Biomedical Research Centre (BRC). ACB acknowledges the support of the UK CF Gene

Therapy Consortium and its funders, in particular the UK National Institute for Health

Research and Department of Health for funding the pGM169/GL67A Phase 2b trial. lonis

CF projects mentioned in this publication received support from the Cystic Fibrosis

Foundation.

\section{REFERENCES}

[1] Ramsey BW, Davies J, McElvaney NG, Tullis E, Bell SC, Drevinek P, et al. A CFTR potentiator in patients with cystic fibrosis and the G551D mutation. N Engl J Med. 2011;365:1663-72.

[2] Wainwright CE, Elborn JS, Ramsey BW. Lumacaftor-Ivacaftor in Patients with Cystic Fibrosis Homozygous for Phe508del CFTR. N Engl J Med. 2015;373:1783-4.

[3] Davies JC, Moskowitz SM, Brown C, Horsley A, Mall MA, McKone EF, et al. VX-659-TezacaftorIvacaftor in Patients with Cystic Fibrosis and One or Two Phe508del Alleles. N Engl J Med. 2018;379:1599-611.

[4] Talamo Guevara M, McColley SA. The safety of lumacaftor and ivacaftor for the treatment of cystic fibrosis. Expert Opin Drug Saf. 2017;16:1305-11.

[5] Griesenbach U, Davies JC, Alton E. Cystic fibrosis gene therapy: a mutation-independent treatment. Curr Opin Pulm Med. 2016;22:602-9.

[6] Cooney AL, McCray PB, Jr., Sinn PL. Cystic Fibrosis Gene Therapy: Looking Back, Looking Forward. Genes (Basel). 2018;9.

[7] Alton EW, Armstrong DK, Ashby D, Bayfield KJ, Bilton D, Bloomfield EV, et al. Repeated nebulisation of non-viral CFTR gene therapy in patients with cystic fibrosis: a randomised, doubleblind, placebo-controlled, phase 2b trial. Lancet Respir Med. 2015;3:684-91.

[8] Alton EW, Beekman JM, Boyd AC, Brand J, Carlon MS, Connolly MM, et al. Preparation for a first-in-man lentivirus trial in patients with cystic fibrosis. Thorax. 2017;72:137-47.

[9] Boucher RC. Cystic fibrosis: a disease of vulnerability to airway surface dehydration. Trends Mol Med. 2007;13:231-40.

[10] Donaldson SH, Boucher RC. Sodium channels and cystic fibrosis. Chest. 2007;132:1631-6. [11] Mall M, Grubb BR, Harkema JR, O'Neal WK, Boucher RC. Increased airway epithelial Na+ absorption produces cystic fibrosis-like lung disease in mice. Nat Med. 2004;10:487-93.

[12] Almaca J, Faria D, Sousa M, Uliyakina I, Conrad C, Sirianant L, et al. High-content siRNA screen reveals global ENaC regulators and potential cystic fibrosis therapy targets. Cell. 2013;154:1390400.

[13] Bangel-Ruland N, Tomczak K, Weber WM. Targeting ENaC as a Molecular Suspect in Cystic Fibrosis. Curr Drug Targets. 2015;16:951-7.

[14] Shei RJ, Peabody JE, Kaza N, Rowe SM. The epithelial sodium channel (ENaC) as a therapeutic target for cystic fibrosis. Curr Opin Pharmacol. 2018;43:152-65.

[15] Fire A, Xu S, Montgomery MK, Kostas SA, Driver SE, Mello CC. Potent and specific genetic interference by double-stranded RNA in Caenorhabditis elegans. Nature. 1998;391:806-11. 
[16] Tagalakis AD, He L, Saraiva L, Gustafsson KT, Hart SL. Receptor-targeted liposome-peptide nanocomplexes for siRNA delivery. Biomaterials. 2011;32:6302-15.

[17] Tagalakis AD, Saraiva L, McCarthy D, Gustafsson KT, Hart SL. Comparison of nanocomplexes with branched and linear peptides for siRNA delivery. Biomacromolecules. 2013;14:761-70.

[18] Writer MJ, Marshall B, Pilkington-Miksa MA, Barker SE, Jacobsen M, Bell PC, et al. Targeted Gene Delivery to Human Airway Epithelial Cells with Synthetic Vectors Incorporating Novel Targeting Peptides Selected by Phage Display. J Drug Target. 2004;12:185-93.

[19] Tagalakis AD, Munye MM, Ivanova R, Chen H, Smith CM, Aldossary AM, et al. Effective silencing of $\mathrm{ENaC}$ by siRNA delivered with epithelial-targeted nanocomplexes in human cystic fibrosis cells and in mouse lung. Thorax. 2018;73:847-56.

[20] Crooke ST. Molecular Mechanisms of Antisense Oligonucleotides. Nucleic Acid Ther. 2017;27:70-7.

[21] Fey RA, Templin MV, McDonald JD, Yu RZ, Hutt JA, Gigliotti AP, et al. Local and systemic tolerability of a 2'O-methoxyethyl antisense oligonucleotide targeting interleukin-4 receptor-alpha delivery by inhalation in mouse and monkey. Inhal Toxicol. 2014;26:452-63.

[22] Karras JG, Crosby JR, Guha M, Tung D, Miller DA, Gaarde WA, et al. Anti-inflammatory activity of inhaled IL-4 receptor-alpha antisense oligonucleotide in mice. Am J Respir Cell Mol Biol. 2007;36:276-85.

[23] Crosby JR, Zhao C, Jiang C, Bai D, Katz M, Greenlee S, et al. Inhaled ENaC antisense oligonucleotide ameliorates cystic fibrosis-like lung disease in mice. J Cyst Fibros. 2017;16:671-80. [24] Liang XH, Shen W, Sun H, Migawa MT, Vickers TA, Crooke ST. Translation efficiency of mRNAs is increased by antisense oligonucleotides targeting upstream open reading frames. Nat Biotechnol. 2016;34:875-80.

[25] Sasaki S, Sun R, Bui HH, Crosby JR, Monia BP, Guo S. Steric Inhibition of 5' UTR Regulatory Elements Results in Upregulation of Human CFTR. Mol Ther. 2019;27:1749-57.

[26] Huang L, Aghajan M, Quesenberry T, Low A, Murray SF, Monia BP, et al. Targeting Translation Termination Machinery with Antisense Oligonucleotides for Diseases Caused by Nonsense Mutations. Nucleic Acid Ther. 2019.

[27] Keenan MM, Huang L, Jordan NJ, Wong E, Cheng Y, Valley HC, et al. Nonsense-mediated RNA Decay Pathway Inhibition Restores Expression and Function of W1282X CFTR. Am J Respir Cell Mol Biol. 2019;61:290-300.

[28] Faustino NA, Cooper TA. Pre-mRNA splicing and human disease. Genes Dev. 2003;17:419-37. [29] Nissim-Rafinia M, Kerem B. Splicing regulation as a potential genetic modifier. Trends Genet. 2002;18:123-7.

[30] Kole R, Krainer AR, Altman S. RNA therapeutics: beyond RNA interference and antisense oligonucleotides. Nat Rev Drug Discov. 2012;11:125-40.

[31] Bennett CF, Swayze EE. RNA targeting therapeutics: molecular mechanisms of antisense oligonucleotides as a therapeutic platform. Annu Rev Pharmacol Toxicol. 2010;50:259-93.

[32] Colella P, Ronzitti G, Mingozzi F. Emerging Issues in AAV-Mediated In Vivo Gene Therapy. Mol Ther Methods Clin Dev. 2018;8:87-104.

[33] Marquez Loza LI, Yuen EC, McCray PB, Jr. Lentiviral Vectors for the Treatment and Prevention of Cystic Fibrosis Lung Disease. Genes (Basel). 2019;10.

[34] Ferrari S, Geddes DM, Alton EW. Barriers to and new approaches for gene therapy and gene delivery in cystic fibrosis. Adv Drug Deliv Rev. 2002;54:1373-93.

[35] Hart SL, Harrison PT. Genetic therapies for cystic fibrosis lung disease. Curr Opin Pharmacol. 2017;34:119-24.

[36] Cooney AL, Thornell IM, Singh BK, Shah VS, Stoltz DA, McCray PB, Jr., et al. A Novel AAVmediated Gene Delivery System Corrects CFTR Function in Pigs. Am J Respir Cell Mol Biol.

2019;61:747-54. 
[37] Yan Z, McCray PB, Jr., Engelhardt JF. Advances in gene therapy for cystic fibrosis lung disease. Hum Mol Genet. 2019;28:R88-R94.

[38] Johler SM, Rejman J, Guan S, Rosenecker J. Nebulisation of IVT mRNA Complexes for Intrapulmonary Administration. PLoS One. 2015;10:e0137504.

[39] Robinson E, MacDonald KD, Slaughter K, McKinney M, Patel S, Sun C, et al. Lipid NanoparticleDelivered Chemically Modified mRNA Restores Chloride Secretion in Cystic Fibrosis. Mol Ther.

2018;26:2034-46.

[40] Dowdy SF. Overcoming cellular barriers for RNA therapeutics. Nat Biotechnol. 2017;35:222-9.

[41] Ruan J, Hirai H, Yang D, Ma L, Hou X, Jiang H, et al. Efficient Gene Editing at Major CFTR Mutation Loci. Molecular therapy Nucleic acids. 2019;16:73-81.

[42] Mention K, Santos L, Harrison PT. Gene and Base Editing as a Therapeutic Option for Cystic Fibrosis-Learning from Other Diseases. Genes (Basel). 2019;10.

[43] Sanz DJ, Hollywood JA, Scallan MF, Harrison PT. Cas9/gRNA targeted excision of cystic fibrosiscausing deep-intronic splicing mutations restores normal splicing of CFTR mRNA. PLoS One. 2017;12:e0184009.

[44] Crane AM, Kramer P, Bui JH, Chung WJ, Li XS, Gonzalez-Garay ML, et al. Targeted correction and restored function of the CFTR gene in cystic fibrosis induced pluripotent stem cells. Stem Cell Reports. 2015;4:569-77.

[45] Schwank G, Koo BK, Sasselli V, Dekkers JF, Heo I, Demircan T, et al. Functional repair of CFTR by CRISPR/Cas9 in intestinal stem cell organoids of cystic fibrosis patients. Cell Stem Cell.

2013;13:653-8.

[46] Maule G, Casini A, Montagna C, Ramalho AS, De Boeck K, Debyser Z, et al. Allele specific repair of splicing mutations in cystic fibrosis through AsCas12a genome editing. Nat Commun.

2019;10:3556.

[47] Ghosh M, Ahmad S, White CW, Reynolds SD. Transplantation of Airway Epithelial Stem/Progenitor Cells: A Future for Cell-Based Therapy. Am J Respir Cell Mol Biol. 2017;56:1-10. [48] Rosen C, Shezen E, Aronovich A, Klionsky YZ, Yaakov Y, Assayag M, et al. Preconditioning allows engraftment of mouse and human embryonic lung cells, enabling lung repair in mice. Nat Med. 2015;21:869-79.

[49] Gui L, Qian H, Rocco KA, Grecu L, Niklason LE. Efficient intratracheal delivery of airway epithelial cells in mice and pigs. Am J Physiol Lung Cell Mol Physiol. 2015;308:L221-8.

[50] Montoro DT, Haber AL, Biton M, Vinarsky V, Lin B, Birket SE, et al. A revised airway epithelial hierarchy includes CFTR-expressing ionocytes. Nature. 2018;560:319-24.

[51] Plasschaert LW, Zilionis R, Choo-Wing R, Savova V, Knehr J, Roma G, et al. A single-cell atlas of the airway epithelium reveals the CFTR-rich pulmonary ionocyte. Nature. 2018;560:377-81.

[52] Engelhardt JF, Yankaskas JR, Ernst SA, Yang Y, Marino CR, Boucher RC, et al. Submucosal glands are the predominant site of CFTR expression in the human bronchus. Nat Genet.

1992;2:240-8. 
FIGURES

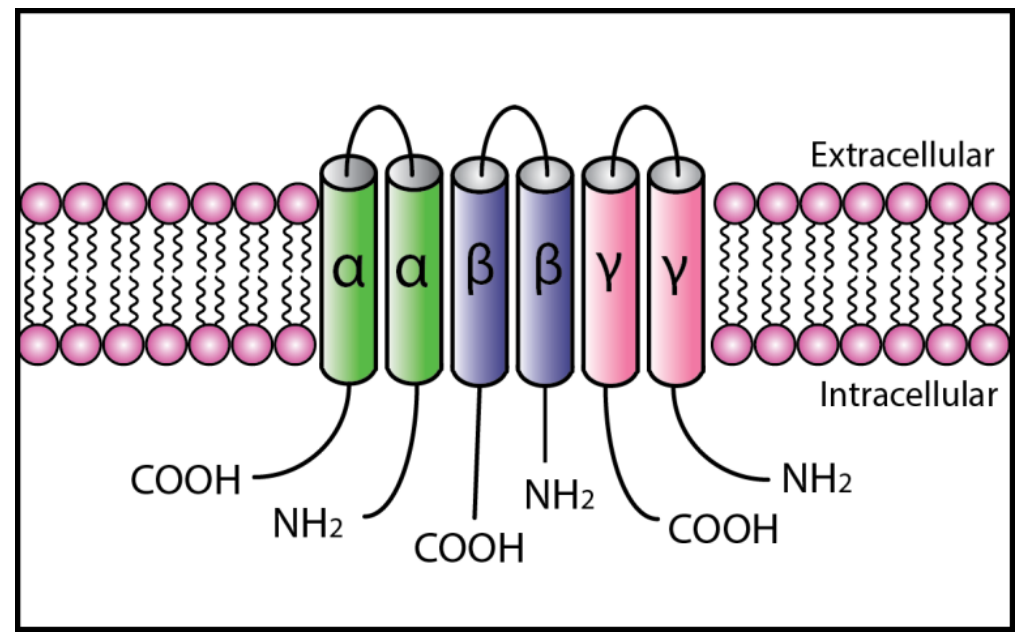

Figure 1. Schematic of the epithelial sodium channel (ENaC). The channel consists of 3 subunits $(\alpha, b$, and $y$ or $\delta)$, with each subunit formed of two transmembrane domains and an extracellular loop. In human airways, ENaC is activated by proteolytic cleavage of the extracellular loops of $\alpha$ and $\gamma$ - subunits. 


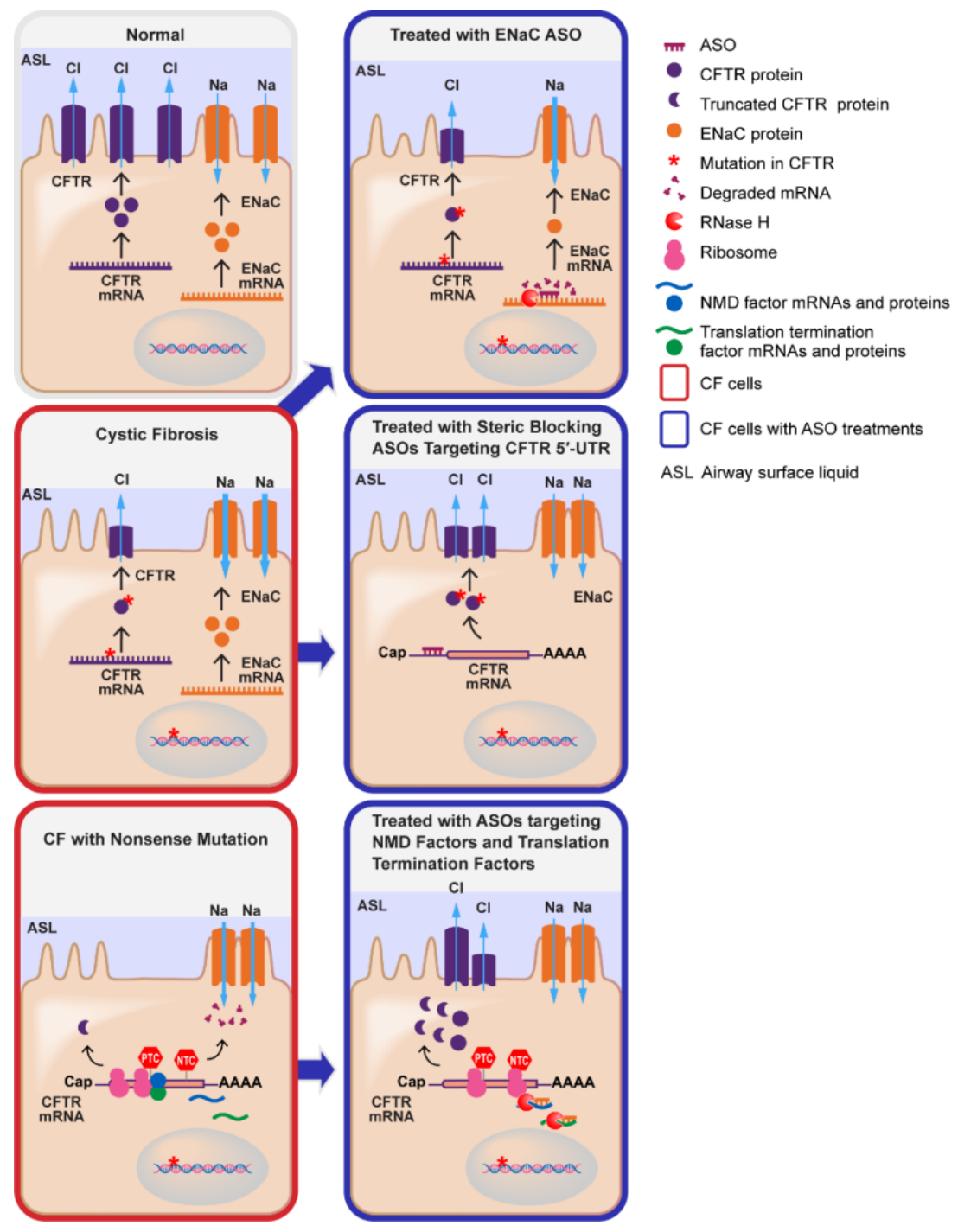

Figure 2. Antisense approaches for cystic fibrosis Illustrations of 1) ASO-mediated reduction of ENaC expression; 2) ASO-mediated upregulation of CFTR translation; 3) ASO-mediated reduction of NMD and translation termination factors that results in upregulation of CFTR expression 
Table 1 Non-viral and Viral Vector Genetic Therapies for Cystic Fibrosis

\begin{tabular}{|l|l|l|l|l|l|}
\hline Non-Viral & $\begin{array}{l}\text { Expression } \\
\text { duration/ } \\
\text { effect }\end{array}$ & $\begin{array}{l}\text { Expression } \\
\text { level }\end{array}$ & $\begin{array}{l}\text { Expression } \\
\text { regulation }\end{array}$ & Safety issues & $\begin{array}{l}\text { Example } \\
\text { References }\end{array}$ \\
\hline CFTR gene & Transient & CFTR +++ & No & Integration, repeat dosing & {$[7]$} \\
\hline CFTR mRNA & Transient & CFTR +++ & No & Frequent repeat dosing & {$[38,39]$} \\
\hline $\begin{array}{l}\text { CFTR gene } \\
\text { editing }\end{array}$ & Stable & $\begin{array}{l}\text { CFTR } \\
\text { normal }\end{array}$ & Yes, native & $\begin{array}{l}\text { Off-target dsbs, Cas9 } \\
\text { immunogenicity }\end{array}$ & {$[41-44]$} \\
\hline $\begin{array}{l}\text { Splice repair/ } \\
\text { anti-sense } \\
\text { oligos }\end{array}$ & Transient & $\begin{array}{l}\text { CFTR } \\
\text { normal }\end{array}$ & Yes, native & Toxicity & {$[24-27]$} \\
\hline $\begin{array}{l}\text { ENaC } \\
\text { oligos/siRNA }\end{array}$ & Transient & ENaC --- & No & $\begin{array}{l}\text { Off target, } \\
\text { immunogenicity }\end{array}$ & {$[19,23]$,} \\
\hline
\end{tabular}

\begin{tabular}{|l|l|l|l|l|l|}
\hline Viral & $\begin{array}{l}\text { Expression } \\
\text { duration/ } \\
\text { effect }\end{array}$ & $\begin{array}{l}\text { Expression } \\
\text { level }\end{array}$ & $\begin{array}{l}\text { Expression } \\
\text { regulation }\end{array}$ & Safety issues & $\begin{array}{l}\text { Example } \\
\text { References }\end{array}$ \\
\hline AAV CFTR gene & Stable & CFTR +++ & No & $\begin{array}{l}\text { Integration (rare), } \\
\text { immunogenicity }\end{array}$ & {$[36]$} \\
\hline LV CFTR gene & Stable & CFTR +++ & No & $\begin{array}{l}\text { Random integration, } \\
\text { oncogenesis } \\
\text { immunogenicity }\end{array}$ & {$[8]$} \\
\hline AAV gene editing & Stable & CFTR normal & Yes, native & $\begin{array}{l}\text { Long term nuclease, } \\
\text { higher risk of off target } \\
\text { dsbs }\end{array}$ & No reports \\
\hline LV gene editing & Stable & CFTR normal & Yes, native & $\begin{array}{l}\text { Long term nuclease, } \\
\text { higher risk of off target } \\
\text { dsbs }\end{array}$ & [46] \\
\hline
\end{tabular}

